\title{
Co-exposure to endocrine disruptors: effect of bisphenol A and soy extract on glucose homeostasis and related metabolic disorders in male mice
}

\author{
Masoud Veissi ${ }^{1,3}$, Sima JAFARIRAD ${ }^{2,3}$, Akram Ahangarpour ${ }^{1,4}$, \\ Seyede Marjan MoH AGHegh ${ }^{1,3,5}$, Amal Saki MaLeHI ${ }^{6}$
}

${ }^{1}$ Diabetes Research Center, Health Research Institute, Ahvaz Jundishapur University of Medical Sciences, Ahvaz, Iran; ${ }^{2}$ Nutrition and Metabolic Diseases Research Center, Ahvaz Jundishapur University of Medical Sciences, Ahvaz, Iran; ${ }^{3}$ Department of Nutrition sciences, School of Para-medicine, Ahvaz Jundishapur University of Medical Sciences, Ahvaz, Iran; ${ }^{4}$ Department of Physiology, School of Medicine, Ahvaz Jundishapur University of Medical Sciences, Ahvaz, Iran;

${ }^{5}$ Student Research Committee of Ahvaz Jundishapur University of Medical Sciences, Ahvaz, Iran;

${ }^{6}$ Department of Biostatistics and Epidemiology, School of Public Health, Ahvaz Jundishapur University of Medical Sciences, Ahvaz, Iran

E-mail:mohaghegh.dietitian@gmail.com

Objectives. Bisphenol A (BPA) is a xenoestrogen, which is commonly used as a monomer of polycarbonate plastics food containers and epoxy resins. Little is known about the interaction effects between xeno- and phyto- estrogens on glucose homeostasis or other metabolic disorders. The aim of this study was to examine effects of individual or combined exposure to low doses of BPA and soy extract on glucose metabolism in mice with the goal to establish its potential mechanisms.

Methods. Fifty-four male mice were randomly divided into six groups. Mice were treated with soy extract at 60 or $150 \mathrm{mg} / \mathrm{kg}$ by daily gavage with or without subcutaneously administration of BPA $(100 \mu \mathrm{g} / \mathrm{kg} /$ day $)$ for four weeks at the same time, while the control group received a vehicle. Serum levels of fasting glucose, insulin, adiponectin, testosterone, malondialdehyde (MDA), and total antioxidant capacity (TAC) were measured. Homeostatic model assessment- $\beta$ cell function (HOMA- $\beta$ ) index was also determined.

Results. BPA exposure induced hyperglycemia and significantly reduced HOMA- $\beta$, serum levels of insulin, adiponectin, testosterone, and TAC and noticeably enhanced MDA in BPA group compared to control one. While treatment with soy extract in high dose $(150 \mathrm{mg} / \mathrm{kg})$ significantly decreased the levels of fasting blood glucose and MDA and notably improved the serum levels of insulin, HOMA- $\beta$, and TAC compared to BPA group.

Conclusion. Soy extract may protect against some adverse effects of BPA. These findings represent the first report suggesting a potential effect between soy extract and BPA in low doses, however, further studies are needed to confirm these results.

Key words: bisphenol-A, endocrine disruptors, glucose, oxidative stress, soybeans, testosterone

Epidemiological studies have reported that human exposure to endocrine disrupting chemicals (EDCs), due to changes in lifestyle and more extensive use of canned foods, has been increasing in recent years
(Choi et al. 2017). According to the Environmental Protection Agency (EPA), these chemicals can disrupt the synthesis, secretion, transport, binding, and action of the natural body hormones that are respon-

Corresponding author: Seyede Marjan Mohaghegh, Diabetes Research Center, Health Research Institute, Ahvaz Jundishapur University of Medical Sciences, Ahvaz, Iran; phone: +98-9163125489; fax: +98-61333738330; e-mail: mohaghegh.dietitian@gmail.com. 
sible for the homeostasis, reproduction, growth, and behavior maintaining (Kavlock et al. 1996). Therefore, an increasing number of studies have been conducted in response to great concerns raised about the possible role of these substances in the etiology of metabolic disorders. Bisphenol A (BPA) is an endocrine disruptor commonly used as a monomer in polycarbonate plastic food containers and epoxy resins coating metallic cans and the exposure to high temperatures and extreme $\mathrm{pH}$ can increase its leaching from cans and bottles into their contents (Brede et al. 2003). Most people are continuously exposed to it through the environment and diet. Biomonitoring studies have reported detectable amounts of BPA at nanomolar levels in human serum (Vandenberg et al. 2007; Choi et al. 2017).

Extensive literature has suggested that BPA is associated with chronic diseases such as diabetes, obesity, hypertension, cardiovascular disease (CVD), reproductive disorders, and cancer (Rezg et al. 2014; Seachrist et al. 2016). Animal experiments have confirmed that BPA exposure may result in an abnormal glucose metabolism, loss of insulin secretion, and insulin resistance (Liu et al. 2013; Song et al. 2014). Alonso-Magdalena et al. (2006) were some of the first researchers who have shown that treatment of male mice with $100 \mu \mathrm{g} / \mathrm{kg} /$ day of BPA or $17 \beta$-estradiol (E2) induced insulin resistance and postprandial hyperinsulinemia. Previously, the majority of studies have considered BPA to be a weak xenoestrogen or environmental estrogen by focusing on nuclear mechanisms of estrogen receptors (ERs) (Fang et al. 2000). The subsequent studies have shown that BPA at low concentrations may induce rapid extra-nuclear responses via ERs located on the plasma membrane and other hormone pathways. These more recent mechanisms have been found in environmentally relevant doses of BPA that are below the pharmacological concentration range (Yoon et al. 2014; Acconcia et al. 2015).

In the real world, we are exposed to mixtures of EDCs, which most are anthropogenic but some, including soy isoflavones, are natural. Isoflavones are the main phytoestrogens in human food and soybean as a rich source has the highest known concentration of isoflavones, including genistein and daidzein (Albini et al. 2014). Soy foods are reported to have numerous health benefits on different biological functions and thus many experts have recommended soy product consumption. Food and Drug Administration (FDA) was the first to formally recognized the benefit of soy protein and suggested daily consumption of $25 \mathrm{~g}$ of soy protein (Anderson and Bush 2011; Messina 2016). Although soy isoflavones are known to be phytoestrogens, they can also exert endocrine disrupting actions through their estrogen agonist/ antagonist properties (Wuttke et al. 2008; Albini et al. 2014).

Soy consumption is growing in popularity and BPA exposure has become continuous and ubiquitous. Therefore it is important to understand how dietary and environmental exposures may interact. Soy isoflavone has been shown to counteract epigenetic changes conferred by early life BPA exposure in the agouti mouse (Dolinoy et al. 2007). Another study has shown that male rats exposed to BPA plus a soy diet, but not BPA alone, had lighter testes (Cao et al. 2015).

Little is known about the interaction effects between xeno- and phyto- estrogens on glucose homeostasis. To the best of our knowledge, no previous study has examined the effects of combined exposure to low doses of BPA and soy extract on glucose biomarkers, oxidative stress status, and reproductive hormone testosterone levels at the same time, especially in male mice. Here, we extensively evaluated the effects of BPA and soy extract on these metabolic parameters, alone and in combination.

\section{Materials and methods}

Extraction of soybeans. Soybeans (Glycine Max) were supplied by Behpak Industrial Company (Behshahr, Iran). It was scientifically identified by a botanist and a voucher specimen (jps017115) was deposited at the Herbarium of the Pharmacognosy Department, School of Pharmacy, Ahvaz Jundishapur University of Medical Sciences (AJUMS). The soybean seeds were ground into small pieces. One kilogram of crumbled seeds was macerated in methanol $80 \%(\mathrm{v} / \mathrm{v})$ (Merck, Germany) at room temperature for $72 \mathrm{~h}$ with intermittent shaking at 2-hour intervals. The extract was filtered through Whatman papers (No. 1) then concentrated by a rotary vacuum evaporator at $40^{\circ} \mathrm{C}$ in order to reduce the volume of the extract. Since the presence of methanol in the extract can influence the animal response, the extract was freeze-dried (OPRFDCF-12012, Operon, Korea) for $48 \mathrm{~h}$ (Giribabu et al. 2014). All processes were performed by the Medicinal Plant Research Center of AJUMS. The soy extract was stored at $10^{\circ} \mathrm{C}$ until time of use. The yield of the plant extraction was $3.74 \%(w / w)$.

Animal treatment. Adult male NMRI mice aged 2-2.5 months $(25-30 \mathrm{~g})$ were obtained from the animal house of AJUMS (Ahvaz, Iran). All experiments and protocols were conducted in accordance with the general guidelines for the use and care of animals used for scientific purposes and approved by the Eth- 
ics Committee of AJUMS (reference No. IR.AJUMS. REC.1394.524). Mice were maintained under standard conditions $\left(22 \pm 2{ }^{\circ} \mathrm{C}, 35 \%-60 \%\right.$ humidity, $12 \mathrm{~h}$ light/12 h dark cycle) with free access to food and water throughout the experimental period. Both water bottles and cages were devoid of BPA. After a 1-week adaptation period, animals were randomly divided into six groups containing nine mice in each as follows: I) negative control group, administered distilled water; II) BPA group, received $100 \mu \mathrm{g} / \mathrm{kg}$ of BPA (2,2Bis 4-hydroxyphenyl propane) (MERCK, Germany); III) soy 1 group, received $60 \mathrm{mg} / \mathrm{kg}$ soy extract; IV) soy 2 group, received $150 \mathrm{mg} / \mathrm{kg}$ soy extract; V) BPA + soy 1 group, received BPA $(100 \mu \mathrm{g} / \mathrm{kg})$ and soy extract $(60 \mathrm{mg} / \mathrm{kg}) ; \mathrm{VI}) \mathrm{BPA}+$ soy 2 group, received BPA $(100 \mu \mathrm{g} / \mathrm{kg})$ and soy extract $(150 \mathrm{mg} / \mathrm{kg})$.

Distilled water containing $0.1 \%$ ethanol was used as the vehicle (Song et al. 2014) for the BPA solution, which was administered subcutaneously for 4 weeks. The soy-treated groups received soy extract by daily gavage feeding for the same time period. BPA (Ahangarpour et al. 2016) and soy extract dosages (Liu et al. 2008; Yu et al. 2010) were chosen based on previous studies.

Blood collection. Twenty-four hours after the last treatment following an overnight fasting period, the mice were anesthetized. Immediately, blood samples were collected through cardiac puncture and centrifuged at $3000 \mathrm{rpm}$ for $20 \mathrm{~min}$, then the serum was separated out and kept at $-80^{\circ} \mathrm{C}$ for subsequent analysis of serum parameters.

Biochemical assays. Fasting blood glucose (FBS) was measured in each sample obtained from the tail vein using an Accu-check compact glucometer (Performa, Germany). Serum insulin concentration was measured by a mouse insulin enzyme-linked immunosorbent assay (ELISA) kit (Mercodia, No. 10-1247-
01 , Sweden). The homeostatic model assessment $\beta$ cell function (HOMA- $\beta$ index) was calculated according to the following formulas (Matthews et al. 1985): [Fasting insulin $(\mathrm{mU} / \mathrm{L}) \times 360] /[\mathrm{FBS}(\mathrm{mg} / \mathrm{dl})-63$ ]

Serum adiponectin level was determined by a mouse ELISA kit (Eastbiopharm, No. CK-E20456, USA) according to the manufacturer's instructions. The serum level of testosterone was assessed using a commercial ELISA mouse kit (BioVendor, No. RTC001R, Czech Republic). A colorimetric assay kit (ZellBio GmbH, No. ZB-TAC-96A, Germany) was used for measurement of serum total antioxidant capacity (TAC), and a colorimetric assay kit (ZellBio GmbH, No. ZB-MDA-96A, Germany) was used to measure the serum level of malondialdehyde (MDA). The TAC concentration was considered as the amount of antioxidant in the sample that compared with ascorbic acid action as the standard.

Statistical Analysis. Data were assessed for normality by the Shapiro-Wilk test, which confirmed normal distribution of data. Statistical evaluation was performed with one-way analysis of variance (ANOVA) followed by a Tukey post-hoc test using SPSS software (version 17.0). The results are presented as mean \pm SEM (standard error of mean) and $p<0.05$ was defined as statistically significant.

\section{Results}

Effect of soy extract and BPA on FBS, insulin level, and HOMA- $\beta$. Administration of BPA caused a reduction in insulin concentration and HOMA- $\beta$ and an increase in FBS level compared with the control group as shown in Table $1(\mathrm{p}<0.01, \mathrm{p}<0.001$, and $\mathrm{p}<0.001$; respectively).

Treatment with both 60 and $150 \mathrm{mg} / \mathrm{kg}$ doses of soy extract significantly reduced FBS levels in the BPA +

Table 1

Effect of bisphenol A (BPA) and soy extract alone or in combination on fasting blood glucose, insulin, adiponectin levels, and homeostatic model assessment- $\beta$ cell function (HOMA- $\beta$ ).

\begin{tabular}{|c|c|c|c|c|}
\hline Groups & $\begin{array}{l}\begin{array}{l}\text { Glucose } \\
(\mathrm{mg} / \mathrm{dl})\end{array} \\
\end{array}$ & $\begin{array}{c}\text { Insulin } \\
(\mu \mathrm{g} / \mathrm{L})\end{array}$ & $\begin{array}{c}\text { Adiponectin } \\
(\mathrm{mg} / \mathrm{L})\end{array}$ & НОМА- $\beta$ \\
\hline Control & $89.77 \pm 3.19^{\# \# \#}$ & $0.66 \pm 0.10^{\# \#}$ & $4.85 \pm 0.43^{\# \#}$ & $135.54 \pm 9.45^{\# \# \#}$ \\
\hline BPA $(100 \mu \mathrm{g} / \mathrm{kg})$ & $138.85 \pm 2.94^{* * *}$ & $0.22 \pm 0.01^{* *}$ & $2.97 \pm 0.21^{* *}$ & $26.88 \pm 2.34^{* * *}$ \\
\hline Soy 1 (60 mg/kg soy extract) & $99.85 \pm 2.29^{\# \# \#}$ & $0.42 \pm 0.04$ & $4.0 \pm 0.27$ & $100.83 \pm 8.28^{\# \#}$ \\
\hline Soy 2 ( $150 \mathrm{mg} / \mathrm{kg}$ soy extract) & $98.50 \pm 2.26^{\# \# \#}$ & $0.45 \pm 0.06$ & $4.09 \pm 0.34$ & $117.32 \pm 20.56^{\# \# \#}$ \\
\hline BPA $(100 \mu \mathrm{g} / \mathrm{kg})+$ Soy $1(60 \mathrm{mg} / \mathrm{kg}$ soy extract $)$ & 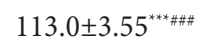 & $0.37 \pm 0.04$ & $3.15 \pm 0.33^{*}$ & $76.23 \pm 12.71^{*}$ \\
\hline BPA $(100 \mu \mathrm{g} / \mathrm{kg})+$ Soy $2(150 \mathrm{mg} / \mathrm{kg}$ soy extract $)$ & $104.42 \pm 1.88^{* \# \# \#}$ & $0.67 \pm 0.17^{\#}$ & $2.87 \pm 0.43^{* *}$ & $105.98 \pm 18.06^{\# \#}$ \\
\hline
\end{tabular}

Results are expressed as mean \pm SEM. One-way ANOVA and post-hoc Tukey tests. ${ }^{\star} \mathrm{p}<0.05,{ }^{* *} \mathrm{p}<0.01,{ }^{* * *} \mathrm{p}<0.001$ vs. control group; $\left.{ }^{\#} \mathrm{p}<0.05\right),{ }^{* \#} \mathrm{p}<0.01,{ }^{\# \# *} \mathrm{p}<0.001$ vs. BPA group. 
soy 1 and BPA + soy 2 groups compared with the BPA group ( $\mathrm{p}<0.001$ and $\mathrm{p}<0.001$, respectively). However, FBS levels were still significantly higher in the BPA + soy $1(\mathrm{p}<0.001)$ and BPA + soy $2(\mathrm{p}<0.05)$ groups than that of the control group. Insulin levels increased after soy treatment in the BPA + soy groups but only the increase in the BPA + soy 2 group was statistically significant $(\mathrm{p}<0.05)$ compared with the BPA group. Also, showing a similar effect, $150 \mathrm{mg} / \mathrm{kg}$ soy extract increased the HOMA- $\beta$ value in BPA + soy 2 group as compared with the BPA group $(\mathrm{p}<0.01)$.

Effect of soy extract and BPA on serum levels of adiponectin. Daily injection of BPA alone remarkably reduced the adiponectin level when compared with the control group $(\mathrm{p}<0.01)$. No increase in adiponectin level was detected in response to soy extract treatment (Table 1).

Effect of soy extract and BPA on serum levels of TAC and MDA. The TAC level declined $(\mathrm{p}<0.05)$ and the MDA level increased $(p<0.001)$ significantly in the BPA group in comparison with control group. TAC levels were significantly higher in the soy $1(\mathrm{p}<0.05)$ and soy $2(\mathrm{p}<0.01)$ groups than in the BPA group. However, only $150 \mathrm{mg} / \mathrm{kg}$ dose extract administration showed a significant increase in TAC $(\mathrm{p}<0.05)$ and a decrease in MDA levels $(\mathrm{p}<0.01)$ in the BPA + soy 2 group compared with BPA group (Figure 1A,B).

Effect of soy extract and BPA on serum levels of testosterone. As shown in Figure 1C, a significant reduction in testosterone concentration was observed in the BPA group in comparison with control group $(p<0.01)$. Moreover, levels of this hormone were significantly lower in the BPA + soy $1(\mathrm{p}<0.01)$ and $\mathrm{BPA}+$ soy2 $(\mathrm{p}<0.01)$ groups than that of control group.

\section{Discussion}

BPA can be easily accumulated in the lipid rich tissues and act as a xenoestrogen or environmental estrogen, which means that it is chemically able to bind to estrogen receptors and exert estrogenic effects (Acconcia et al. 2015). It is noteworthy that previ-

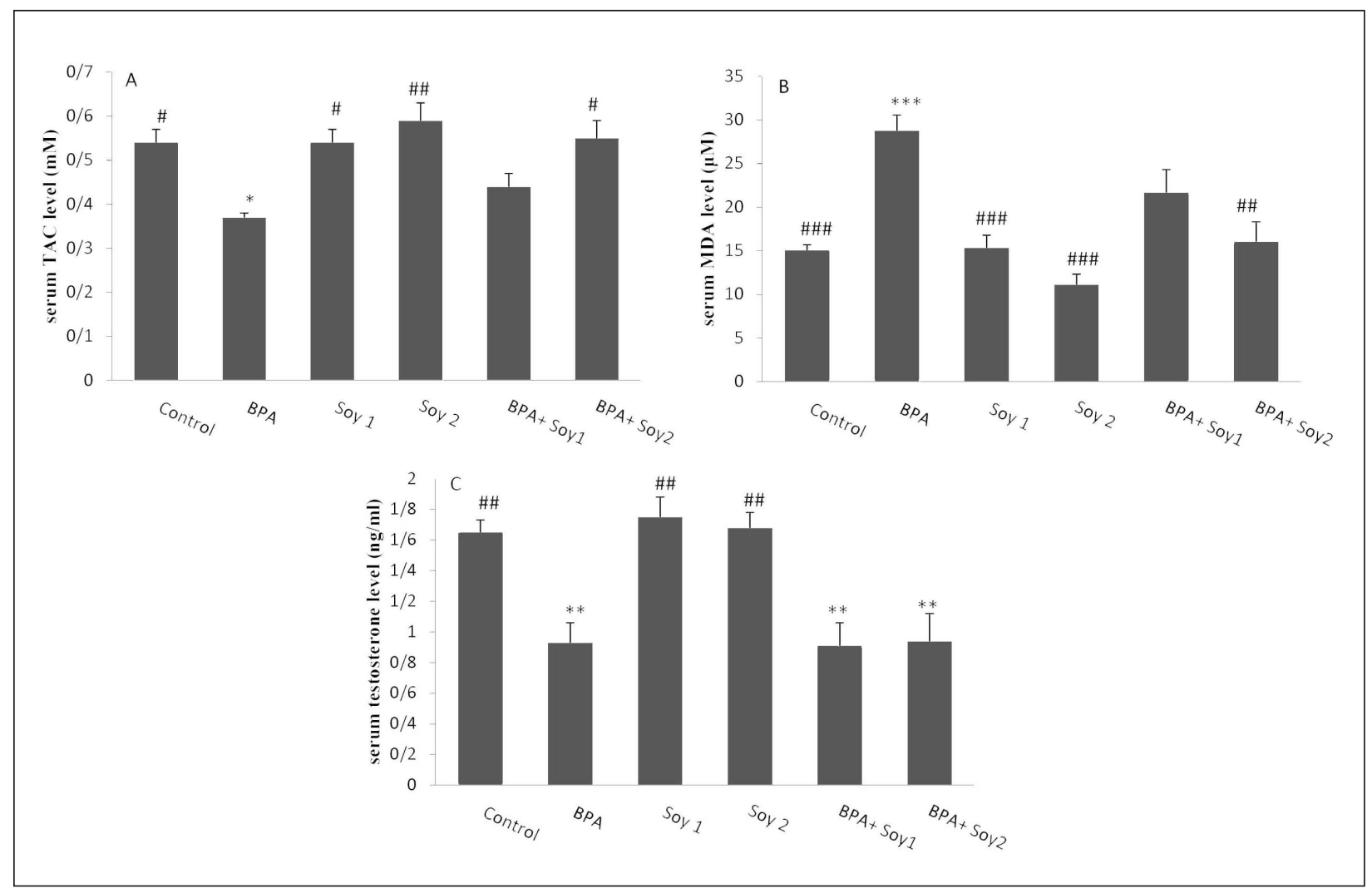

Figure 1. Effect of bisphenol A (BPA) and soy extract alone and in combination on (A) total antioxidant capacity (TAC); (B) malondialdehyde (MDA); (C) testosterone serum levels. Results are expressed as mean \pm SEM. One-way ANOVA and Tukey test. ${ }^{\#} \mathrm{p}<0.05$ vs. BPA group, ${ }^{* \#} \mathrm{p}<0.01$ vs. BPA group, ${ }^{\# * \#} \mathrm{p}<0.001$ vs. BPA group. ${ }^{*} \mathrm{p}<0.05$ vs. control group, ${ }^{* *} \mathrm{p}<0.01$ vs. control group, ${ }_{* * *} \mathrm{p}<0.001$ vs. control group. Soy 1 : soy extract $60 \mathrm{mg} / \mathrm{kg}$; soy 2 : soy extract $150 \mathrm{mg} / \mathrm{kg}$; BPA + soy 1: BPA $100 \mu \mathrm{gg} / \mathrm{kg}+$ soy extract $60 \mathrm{mg} / \mathrm{kg} ; \mathrm{BPA}+$ soy $2: \mathrm{BPA} 100 \mu \mathrm{g} / \mathrm{kg}+$ soy extract $150 \mathrm{mg} / \mathrm{kg}$. 
ous studies have focused more on interaction effects between BPA and soy on reproductive hormones. However these compounds could also have potential influences on gluco-regulatory hormones due to endocrine disruptive properties. Therefore, in the current study, we evaluated the effect of co-exposure to estrogen active chemicals (EAC) on glucose homeostasis in an animal model. The possible biochemical mechanisms were studied by measuring the serum levels of testosterone, TAC, and MDA.

In this study, BPA exposure resulted in an abnormal glucose homeostasis through decreased insulin and elevated glucose levels. The same finding has been also shown by Ahangarpour et al. (2016), who have reported pancreatic cell apoptosis, hyperglycemia, and a reduction in insulin secretion induced by $100 \mu \mathrm{g} / \mathrm{kg}$ of BPA, which is the same dose that we used.

On the other hand, some experimental studies data, slightly different from our one, have found hyperinsulinemia and insulin resistance in BPA-treated mice (Alonso-Magdalena et al. 2006; Angle et al. 2013; Song et al. 2014). This rather contradictory result may be due to differences between strains of mice, because there is a strong evidence that the effects of BPA vary with duration, doses, route of exposure, species, and sex (Liu et al. 2013).

BPA exposure strongly decreased HOMA- $\beta$ in comparison with the intact mice in the control, soy 1 and soy 2 groups in this study. HOMA- $\beta$ is a valid and widely used index to evaluate the function of islet $\beta$-cells in pancreas and insulin secretion. The lower are HOMA- $\beta$ score, the more serious $\beta$-cell injuries represent. Our results for HOMA- $\beta$ also confirmed inability of pancreatic insulin secretion following BPA administration.

Our findings demonstrate that soy extracts could attenuate glucose metabolism dysfunction in mice co-exposed to BPA and soy extract via modulating reduction of FBS and increments of insulin concentration and HOMA- $\beta$ with a greater effect at higher dose of soy extract. Several studies have confirmed that BPA exposure is associated with mitochondrial defects leading impairment and failure of pancreatic $\beta$-cells. Indeed, BPA induces dysfunction of insulin secretion and apoptosis through the damage of mitochondria. They have also reported disruption of mRNA expression of genes playing a key role in $\beta$-cell function (Glut2, Gck, Pdx1 and Snap25), and mitochondrial function (Ucp2 and Ogdh) (Song et al. 2012; Lin et al. 2013).

Accumulating evidence supports the health benefits of soy, which can be widely attributed to the pres- ence of isoflavones in the soybean. Soy isoflavones have direct effect on $\beta$-cells proliferation, providing protection against apoptosis and glucose-stimulated insulin secretion (Gilbert and Liu 2013). Interestingly, some evidence suggested that the insulinotropic effect and $\beta$-cell proliferation related to soy isoflavones are neither dependent on its known activities as an antioxidant nor estrogen receptor agonist but are mediated via activation of the CAMP-dependent protein kinase (cAMP/PKA) cascade. Genistein could increase intracellular cAMP, PKA activity, and active extracellular signal-regulated protein kinases 1 and 2 (ERK1/2). These actions lead to enhancement in the protein expression of cyclin D1, a major cellcycle regulator in $\beta$-cell growth. Elevation of cAMP also activates some factors, which contribute to insulin exocytosis (Fu et al. 2010).

Soy isoflavones also reduce hyperglycemia with the probable mechanisms of activating glucose transporter-4 (Glut4) translocation to plasma membrane and mitochondrial biogenesis modulated by the AMP-activated protein kinase (AMPK) pathway (Cederroth et al. 2008; Cheong et al. 2014).

BPA has shown that reduced expression of Pdx1 and Glut2 mRNA while Procyanidin A2 known as a member of polyphenolic family increased mRNA levels of these genes. So, the mechanisms, by which isoflavones may exert their physiological effects on glucose transports appear to be common with those of the other polyphenols (Yang et al. 2015; Ahangarpour et al. 2016). These findings suggest possible mechanisms that soy extract $(150 \mathrm{mg} / \mathrm{kg})$ could possibly normalize the level of glycemia along with providing an ability to protect $\beta$-cells function in mice simultaneously exposed to BPA and soy in the current study.

Although the FBS was within the normal range in animals treated by soy extracts alone, a slight but not significant increase in FBS was observed. Interestingly, higher baseline glucose levels in animals reared on a soy diet, not BPA was observed by Patisaul et al. (2014). It has been proposed that either excessive or abnormal concentrations of chemicals with estrogenic activity can enhance the risk of diabetes (AlonsoMagdalena et al. 2006). On this basis, interpretation of the results may be complicated and it may be difficult to accurately predict the responses based only on the estrogenic effect. Therefore, extensive studies should be performed to verify the dose-response mechanisms for this effect.

Adiponectin levels in all BPA exposure groups including BPA, BPA + soy 1 and $\mathrm{BPA}+$ soy 2 were significantly lower than in the control and showed the 
soy extract could not alter relatively strong effect of BPA on this hormone observed in the current study. Adiponectin is an adipokine involved in a number of metabolic processes, including glucose regulation, activation of insulin signal pathways such as AMPK, and fatty acid oxidation (Wang et al. 2013). In agreement with the earlier studies (Angle et al. 2013; Song et al. 2014), the decreased levels of adiponectin induced by BPA in our study, is a critical factor in mediating hyperglycemia. The underlying mechanisms for BPA action in inhibiting adiponectin secretion are not clearly established, but it could be due to the effects of BPA on adipocyte differentiation and interference with glucose homeostasis in adipocytes (Sakurai et al. 2004; Ariemma et al. 2016). A more recent research has pointed out that BPA could interact with nuclear receptors known as peroxisome proliferator-activated receptors (PPARs). PPARs contribute in the pathology of diabetes through dysregulation of adipocytokines such as adiponectin (Song et al. 2014; Li et al. 2015). Therefore, it is hypothesized that BPA probably due to this mechanism, may affect the adiponectin secretion. Such activity requires to be confirmed both in vivo and in vitro conditions.

Both BPA and soy phytoestrogen are able to interact with PPARs, but they are considered to have different consequences, surprisingly. Since soy has been reported to act as PPAR activator that can lead to up-regulation of adiponectin gene expression and increase adiponectin secretion (Oliva et al. 2015; Sakamoto et al. 2016). However, we found that soy extract of $60 \mathrm{mg} / \mathrm{kg}$ and $150 \mathrm{mg} / \mathrm{kg}$ did not alter serum adiponectin levels. This may possibly be due to the relatively short period of time of soy extract treatment. Further studies with a longer duration are required to determine whether similar results are found.

In recent years, a large number of experimental studies have been undertaken to establish the possible mechanisms of BPA. They have suggested that independent of an estrogenic effect, BPA can disrupt the oxidant-antioxidant balance. Nrf2 transcription pathway is a known underlying mechanism of the BPA-mediated effect upon antioxidant enzyme activity. Both BPA and soy isoflavones trigger this pathway. Soy isoflavone can attenuate oxidative stress via regulation of the Nrf2 and PPAR $\gamma$ signaling pathway (Zhang et al. 2013; Bosch-Panadero et al. 2018).

In the present study, BPA exposure induced oxidative stress both by TAC and MDA. Oxidative stress is caused by an imbalance between reactive oxygen species (ROS) and antioxidant defense system's ability to scavenge the reactive intermediates or to repair the consequence damages. TAC is an assay widely used to determine the antioxidant status. MDA is also an indicator of oxidative stress that is produced from lipid peroxidation. One of our study limitations is measurement of only TAC. We did not measure all antioxidant components and therefore, our study can only provide limited information about the antioxidant status. For example, this method does not evaluate the role of enzymes such as superoxide dismutase and catalase. Treatment with a dose of $150 \mathrm{mg} / \mathrm{kg}$ soy extract slightly changed TAC and MDA levels in the animals in the soy 2 group in comparison with control group. However, this dose had significantly greater effect when the animals were simultaneously exposed to BPA and soy. Our results are consistent with the experimental studies reporting on a link between BPA exposure and oxidative stress. In a similar study, Popa et al. (2014) have shown that Genista tinctoria by its antioxidant properties owing to rich isoflavones, could reduce MDA and hydroxyl radical generation induced by BPA.

Overproduction of oxidative stress could lead to damage of pancreatic $\beta$-cells, which are responsible for insulin biosynthesis and secretion (Ahangarpour et al. 2016). Therefore, it seems that oxidative stress may be associated with glucose metabolism dysfunction induced by BPA in the present study. Isoflavones in soybeans could protect cells from damage through its antioxidant potential. As our results showed, a dose of $150 \mathrm{mg} / \mathrm{kg}$ soy extract could improve $\beta$-cell function and subsequently recover insulin and glucose levels, probably by reducing oxidative stress in these cells.

Effects on sex hormone levels through their ability to bind to estrogen and androgen receptors is one of the main mechanisms of BPA proposed by earlier studies (Acconcia et al. 2015). Moreover, it has been reported that testosterone deficiency is common in men with diabetes, regardless of the type of diabetes (Grossmann et al. 2008). For these reasons, we aimed to evaluate testosterone levels in male mice due to the scope of this investigation. In the current study, soy extract treatment did not alter serum levels of testosterone, whereas BPA noticeably reduced this hormone in all exposed BPA groups. Our finding supports previous work by Chouhan et al. (2015) who have reported that sperm count and serum testosterone level were reduced in treated mice by $100 \mu \mathrm{g} / \mathrm{kg}$ BPA.

It is likely that BPA may down-regulate steroidogenic acute regulatory protein (StAR) expression, leading to a decrease in testosterone biosynthesis. StAR is a transport protein primarily present in steroid-producing cells that is involved in the production of steroid hormones. In addition, BPA can prob- 
ably suppress testosterone production via activation of oxidative stress (Chouhan et al. 2015). Similarly, data from present study revealed that oxidative stress might be responsible for reduced testosterone due to BPA exposure.

In agreement with our finding, Piotrowska et al. (2011) did not find any change in testosterone levels of rats treated with soy isoflavones despite the high dose used and the fact that exposure was during the critical prenatal life to sexual maturity period. In general, some studies have implied that there is an antioxidant potential role of soy isoflavones for improving the inflammatory and oxidative effects of BPA on the gonad (Zhang et al. 2014; Bernardo et al. 2015), and thus soy isoflavones can maintain proper function of the male reproductive system. In contrary, a few studies have also indicated isoflavones reduced fertility and sperm quality along with a possibly antiandrogenic effect (Meena et al. 2017) that cannot be ignored in this context.

In summary, several lines of evidence from our study suggested the protective effect of soy extract $(150 \mathrm{mg} / \mathrm{kg})$ on glucose metabolism dysfunction induced by BPA in mice co-exposed to BPA and soy extract. Further study on the molecular mechanisms underlying interaction effect of BPA and soy on glucose homeostasis will help understanding of the concerns associated with exposure to mixtures of EDCs.

\section{Conclusion}

BPA exposure caused a metabolic disorder along with increased oxidative stress in male mice. This study has been unable to demonstrate a possibility for synergic actions between soy extract and BPA because soy extract treatment could attenuate some adverse effects induced by BPA. Taken together, findings from this study highlighting that in agreement with earlier studies, significant effects of BPA in rodents at very low doses draws attention to potential risk in humans. Additional studies should be performed to establish the influence of endocrine disruptors in people at risk of high exposure such as infants fed soy-based formula by plastic bottles, chemical industry workers, and cashiers.

\section{Acknowledgements}

This study is taken from the MSc. thesis of SeyedeMarjan Mohaghegh, and the financial support was provided by a grant (D-9408) from Vice-Chancellor for Research Affairs of Ahvaz Jundishapur University of Medical Sciences. The authors would like to thank Diabetes Research Center, Health Research Institute, and Medicinal Plant Research Center of AJUMS. The authors greatly appreciate Dr. Mehrangiz Chehrazi for technical support.

\section{References}

Acconcia F, Pallottini V, Marino M. Molecular mechanisms of action of BPA. Dose Response 13, 1559325815610582, 2015.

Ahangarpour A, Afshari G, Mard SA, Khodadadi A, Hashemitabar M. Preventive effects of procyanidin A2 on glucose homeostasis, pancreatic and duodenal homebox 1, and glucose transporter 2 gene expression disturbance induced by bisphenol A in male mice. J Physiol Pharmacol 67, 243-252, 2016.

Albini A, Rosano C, Angelini G, Amaro A, Esposito AI, Maramotti S, Noonan DM, Pfeffer U. Exogenous hormonal regulation in breast cancer cells by phytoestrogens and endocrine disruptors. Curr Med Chem 21, 11291145, 2014.

Alonso-Magdalena P, Morimoto S, Ripoll C, Fuentes E, Nadal A. The estrogenic effect of bisphenol A disrupts pancreatic beta-cell function in vivo and induces insulin resistance. Environ Health Perspect 114, 106-112, 2006.

Anderson JW, Bush HM. Soy protein effects on serum lipoproteins: a quality assessment and meta-analysis of randomized, controlled studies. J Am Coll Nutr 30, 79-91, 2011.

Angle BM, Do RP, Ponzi D, Stahlhut RW, Drury BE, Nagel SC, Welshons WV, Besch-Williford CL, Palanza P, Parmigiani S, Vom Saal FS, Taylor JA. Metabolic disruption in male mice due to fetal exposure to low but not high doses of bisphenol A (BPA): evidence for effects on body weight, food intake, adipocytes, leptin, adiponectin, insulin and glucose regulation. Reprod Toxicol 42, 256-268, 2013.

Ariemma F, D’esposito V, Liguoro D, Oriente F, Cabaro S, Liotti A, Cimmino I, Longo M, Beguinot F, Formisano P, Valentino R. Low-dose bisphenol-A impairs adipogenesis and generates dysfunctional 3T3-L1 adipocytes. PLoS One 11, e0150762, 2016.

Bernardo BD, Brandt JZ, Grassi TF, Silveira LT, Scarano WR, Barbisan LF. Genistein reduces the noxious effects of in utero bisphenol A exposure on the rat prostate gland at weaning and in adulthood. Food Chem Toxicol 84, 64-73, 2015. 
Bosch-Panadero E, Mas S, Civantos E, Abaigar P, Camarero V, Ruiz-Priego A, Ortiz A, Egido J, Gonzalez-Parra E. Bisphenol $\mathrm{A}$ is an exogenous toxin that promotes mitochondrial injury and death in tubular cells. Environ Toxicol 33, 325-332, 2018.

Brede C, Fjeldal P, Skjevrak I, Herikstad H. Increased migration levels of bisphenol A from polycarbonate baby bottles after dishwashing, boiling and brushing. Food Addit Contam 20, 684-689, 2003.

Cao J, Echelberger R, Liu M, Sluzas E, Mccaffrey K, Buckley B, Patisaul HB. Soy but not bisphenol A (BPA) or the phytoestrogen genistin alters developmental weight gain and food intake in pregnant rats and their offspring. Reprod Toxicol 58, 282-294, 2015.

Cederroth CR, Vinciguerra M, Gjinovci A, Kuhne F, Klein M, Cederroth M, Caille D, Suter M, Neumann D, James RW, Doerge DR, Wallimann T, Meda P, Foti M, Rohner-Jeanrenaud F, Vassalli JD, Nef S. Dietary phytoestrogens activate AMP-activated protein kinase with improvement in lipid and glucose metabolism. Diabetes 57, 1176-1185, 2008.

Cheong SH, Furuhashi K, Ito K, Nagaoka M, Yonezawa T, Miura Y, Yagasaki K. Daidzein promotes glucose uptake through glucose transporter 4 translocation to plasma membrane in L6 myocytes and improves glucose homeostasis in Type 2 diabetic model mice. J Nutr Biochem 25, 136-143, 2014.

Choi J, Knudsen LE, Mizrak S, Joas A. Identification of exposure to environmental chemicals in children and older adults using human biomonitoring data sorted by age: Results from a literature review. Int J Hyg Environ Health 220, 282-298, 2017.

Chouhan S, Yadav SK, Prakash J, Westfall S, Ghosh A, Agarwal NK, Singh SP. Increase in the expression of inducible nitric oxide synthase on exposure to bisphenol A: a possible cause for decline in steroidogenesis in male mice. Environ Toxicol Pharmacol 39, 405-416, 2015.

Dolinoy DC, Huang D, Jirtle RL. Maternal nutrient supplementation counteracts bisphenol A-induced DNA hypomethylation in early development. Proc Natl Acad Sci U S A 104, 13056-13061, 2007.

Fang H, Tong W, Perkins R, Soto AM, Prechtl NV, Sheehan DM. Quantitative comparisons of in vitro assays for estrogenic activities. Environ Health Perspect 108, 723-729, 2000.

Fu Z, Zhang W, Zhen W, Lum H, Nadler J, Bassaganya-Riera J, Jia Z, Wang Y, Misra H, Liu D. Genistein induces pancreatic beta-cell proliferation through activation of multiple signaling pathways and prevents insulindeficient diabetes in mice. Endocrinology 151, 3026-3037, 2010.

Gilbert ER, Liu D. Anti-diabetic functions of soy isoflavone genistein: mechanisms underlying its effects on pancreatic beta-cell function. Food Funct 4, 200-212, 2013.

Giribabu N, Kumar KE, Rekha SS, Muniandy S, Salleh N. Chlorophytum borivilianum root extract maintains near normal blood glucose, insulin and lipid profile levels and prevents oxidative stress in the pancreas of streptozotocin-induced adult male diabetic rats. Int J Med Sci 11, 1172-1184, 2014.

Grossmann M, Thomas MC, Panagiotopoulos S, Sharpe K, Macisaac RJ, Clarke S, Zajac JD, Jerums G. Low testosterone levels are common and associated with insulin resistance in men with diabetes. J Clin Endocrinol Metab 93, 1834-1840, 2008.

Kavlock RJ, Daston GP, Derosa C, Fenner-Crisp P, Gray LE, Kaattari S, Lucier G, Luster M, Mac MJ, Maczka C, Miller R, Moore J, Rolland R, Scott G, Sheehan DM, Sinks T, Tilson HA. Research needs for the risk assessment of health and environmental effects of endocrine disruptors: a report of the U.S. EPA-sponsored workshop. Environ Health Perspect 104 Suppl 4, 715-740, 1996.

Li L, Wang Q, Zhang Y, Niu Y, Yao X, Liu H. The molecular mechanism of bisphenol A (BPA) as an endocrine disruptor by interacting with nuclear receptors: insights from molecular dynamics (MD) simulations. PLoS One 10, e0120330, 2015.

Lin Y, Sun X, Qiu L, Wei J, Huang Q, Fang C, Ye T, Kang M, Shen H, Dong S. Exposure to bisphenol A induces dysfunction of insulin secretion and apoptosis through the damage of mitochondria in rat insulinoma (INS-1) cells. Cell Death Dis 4, e460, 2013.

Liu Z, Zhang X, Li L, Zhang W, Cui W, Song Y, Wang W, Jia X, Li N, Yan W. Effects of lactational exposure to soy isoflavones on reproductive system in neonatal female rats. Basic Clin Pharmacol Toxicol 102, 317-324, 2008.

Liu J, Yu P, Qian W, Li Y, Zhao J, Huan F, Wang J, Xiao H. Perinatal bisphenol A exposure and adult glucose homeostasis: identifying critical windows of exposure. PLoS One 8, e64143, 2013.

Matthews DR, Hosker JP, Rudenski AS, Naylor BA, Treacher DF, Turner RC. Homeostasis model assessment: insulin resistance and beta-cell function from fasting plasma glucose and insulin concentrations in man. Diabetologia 28, 412-419, 1985.

Meena R, Supriya C, Pratap Reddy K, Sreenivasula Reddy P. Altered spermatogenesis, steroidogenesis and suppressed fertility in adult male rats exposed to genistein, a non-steroidal phytoestrogen during embryonic development. Food Chem Toxicol 99, 70-77, 2017. 
Messina M. Soy and Health Update: Evaluation of the Clinical and Epidemiologic Literature. Nutrients 8, 2016.

Oliva ME, Chicco A, Lombardo YB. Mechanisms underlying the beneficial effect of soy protein in improving the metabolic abnormalities in the liver and skeletal muscle of dyslipemic insulin resistant rats. Eur J Nutr 54, 407-419, 2015.

Patisaul HB, Mabrey N, Adewale HB, Sullivan AW. Soy but not bisphenol A (BPA) induces hallmarks of polycystic ovary syndrome (PCOS) and related metabolic co-morbidities in rats. Reprod Toxicol 49, 209-218, 2014.

Piotrowska K, Baranowska-Bosiacka I, Marchlewicz M, Gutowska I, Nocen I, Zawislak M, Chlubek D, Wiszniewska B. Changes in male reproductive system and mineral metabolism induced by soy isoflavones administered to rats from prenatal life until sexual maturity. Nutrition 27, 372-379, 2011.

Popa DS, Bolfa P, Kiss B, Vlase L, Paltinean R, Pop A, Catoi C, Crisan G, Loghin F. Influence of Genista tinctoria L. or methylparaben on subchronic toxicity of bisphenol A in rats. Biomed Environ Sci 27, 85-96, 2014.

Rezg R, El-Fazaa S, Gharbi N, Mornagui B. Bisphenol A and human chronic diseases: current evidences, possible mechanisms, and future perspectives. Environ Int 64, 83-90, 2014.

Sakamoto Y, Kanatsu J, Toh M, Naka A, Kondo K, Iida K. The Dietary Isoflavone Daidzein Reduces Expression of Pro-Inflammatory Genes through PPARalpha/gamma and JNK Pathways in Adipocyte and Macrophage Co-Cultures. PLoS One 11, e0149676, 2016.

Sakurai K, Kawazuma M, Adachi T, Harigaya T, Saito Y, Hashimoto N, Mori C. Bisphenol A affects glucose transport in mouse 3T3-F442A adipocytes. Br J Pharmacol 141, 209-214, 2004.

Seachrist DD, Bonk KW, Ho SM, Prins GS, Soto AM, Keri RA. A review of the carcinogenic potential of bisphenol A. Reprod Toxicol 59, 167-182, 2016.

Song L, Xia W, Zhou Z, Li Y, Lin Y, Wei J, Wei Z, Xu B, Shen J, Li W, Xu S. Low-level phenolic estrogen pollutants impair islet morphology and beta-cell function in isolated rat islets. J Endocrinol 215, 303-311, 2012.

Song S, Zhang L, Zhang H, Wei W, Jia L. Perinatal BPA exposure induces hyperglycemia, oxidative stress and decreased adiponectin production in later life of male rat offspring. Int J Environ Res Public Health 11, 37283742, 2014.

Vandenberg LN, Hauser R, Marcus M, Olea N, Welshons WV. Human exposure to bisphenol A (BPA). Reprod Toxicol 24, 139-177, 2007.

Wang T, Mao X, Li H, Qiao S, Xu A, Wang J, Lei S, Liu Z, Ng KF, Wong GT, Vanhoutte PM, Irwin MG, Xia Z. NAcetylcysteine and allopurinol up-regulated the Jak/STAT3 and PI3K/Akt pathways via adiponectin and attenuated myocardial postischemic injury in diabetes. Free Radic Biol Med 63, 291-303, 2013.

Wuttke W, Jarry H, Becker T, Schultens A, Christoffel V, Gorkow C, Seidlova-Wuttke D. Phytoestrogens: endocrine disrupters or replacement for hormone replacement therapy? Maturitas 61, 159-170, 2008.

Yang X, Yang J, Xu C, Huang M, Zhou Q, Lv J, Ma X, Ke C, Ye Y, Shu G, Zhao P. Antidiabetic effects of flavonoids from Sophora flavescens EtOAc extract in type 2 diabetic KK-ay mice. J Ethnopharmacol 171, 161-170, 2015.

Yoon K, Kwack SJ, Kim HS, Lee BM. Estrogenic endocrine-disrupting chemicals: molecular mechanisms of actions on putative human diseases. J Toxicol Environ Health B Crit Rev 17, 127-174, 2014.

Yu B, Chen QF, Liu ZP, Xu HF, Zhang XP, Xiang Q, Zhang WZ, Cui WM, Zhang X, Li N. Estrogen receptor alpha and beta expressions in hypothalamus-pituitary-ovary axis in rats exposed lactationally to soy isoflavones and bisphenol A. Biomed Environ Sci 23, 357-362, 2010.

Zhang T, Wang F, Xu HX, Yi L, Qin Y, Chang H, Mi MT, Zhang QY. Activation of nuclear factor erythroid 2-related factor 2 and PPARgamma plays a role in the genistein-mediated attenuation of oxidative stress-induced endothelial cell injury. Br J Nutr 109, 223-235, 2013.

Zhang LD, Li HC, Chong T, Gao M, Yin J, Fu DL, Deng Q, Wang ZM. Prepubertal exposure to genistein alleviates di(2-ethylhexyl) phthalate induced testicular oxidative stress in adult rats. Biomed Res Int 2014, 598630, 2014. 